\title{
Community Share Ownership Trust scheme and empowerment: The case of Gwanda Rural district, Matabeleland South Province in Zimbabwe.
}

\author{
Dr Clifford Mabhena, Mr Funa Moyo \\ Institute of Development Studies-National University of Science and Technology-Bulawayo, Zimbabwe. \\ Institute of Development Studies-National University of Science and Technology-Bulawayo, Zimbabwe
}

\begin{abstract}
The article primarily analyses the effectiveness of social and economic empowerment strategies targeted at the community of Gwanda Rural district. Despite abundant mineral resources, the indigenous communities living close to the mines have been deprived of the right to directly or indirectly benefit from the mineral resources. The study utilised a descriptive survey to collect data. The article gives a strong indication of how communities of Gwanda Rural district can utilise the Indigenisation and Economic Empowerment Act and the Statutory Instrument 21 of 2010 (Community Share Ownership Trust) to empower themselves. The Indigenisation and Economic Empowerment Act and the Community Share Ownership Trusts as the major strategies currently adopted by the Government of Zimbabwe to empower local communities were evaluated. The findings of the study indicated that the Indigenisation and Economic Empowerment Act and Statutory Instrument for Community Share Ownership Trust were the pro poor mining policies that ensured the harnessing of mineral resources for the empowerment of local indigenous communities. It was also found out that the Indigenisation and Economic Empowerment Act needed to be harmonised with the Rural District Councils' Act, the Mines and Minerals Act, and the Communal Areas Management Act. The article concluded that the development of infrastructure and provision of public utilities such as electricity, water, establishing micro-credit to small and medium enterprises and implementing broad-based indigenisation policies were some of the strategies of improving rural livelihoods and stimulating entrepreneurship in communities living close to mines. Similarly direct and indirect linkages between the mining sector and local economy could be enhanced through the provision of food supply to the mine, manufacture of mining inputs, provision of security services and supply of labour by the local community. The article recommends that the harmonisation of these acts will ensure that empowerment is integrated in all legislation focused on rural development and promote sustainable ways of utilising the Community Share Ownership Trusts.
\end{abstract}

Key Words: Empowerment, indigenisation, Community share ownership.

\section{Introduction}

Africa is characterised by high levels of poverty and underdevelopment in spite of the abundant mineral resources, (The Zimbabwe Mining Indaba, 2012). The range of natural resources refers to nonrenewable resources such as oil, gas, mineral and metals, (Andres Mejia, 2011).

Martin and Taylor (2012) revealed that, mining has a huge potential to either contribute significantly to poverty reduction and social and economic empowerment. According to Bryan and Hofmann (2007) mineral wealth must be used for broad development purposes that improve the lives of citizens. Bryn and Hofmann, (2007) further advanced that if well managed, revenues from the mineral wealth could help alleviate poverty and spur development in many countries that, despite their wealth are currently near the bottom of international human development indicator rankings. Andres Mejia (2011) concurred with Bryan and Hofmann (2007) when he declared that mineral resources if well invested could alleviate socio-economic inequalities among citizens. According to Bryan and Hofmann (2007) countries that have successfully used proceeds from the extractive industries for national development purposes, includes Australia, Canada and Norway and these have standards of accountability and transparency. Botswana is widely perceived as a model of the successful management of natural resources for development. The resource-rich countries like Botswana have financed collective goods mainly through mineral rents rather than aid, (O'Connell and Lindsay, 2011). Bryan and Hofmann (2007:24) add that, "since the discovery of diamonds in 1967, diamond revenues have helped fund investments in infrastructure, education, health and other development programs". The ANC Policy Discussion Document (2012) concurs with Bryan and Hofmann (2007) when it declares that mineral resources can be used as a basis for industrialization, job creation, poverty eradication, capacity building and community empowerment and improvement of people's lives. Hence the ANC Policy Discussion Document (2012) and Bryan and Hofmann(2007) address issues of harnessing mineral resources for economic development and community 
empowerment which is central in improving the quality of life for all citizens. Community Share Ownership Trusts (CSTOs) in Zimbabwe have been used as vehicles of broad based community social and economic empowerment. The study argues that CSTOs can be used as tools to harness mineral resources for social and economic empowerment in Zimbabwe in general and Gwanda Rural district in particular.

\section{Empowerment Schemes in Southern Africa}

Mining in Africa should centre on empowering communities in the mining regions to achieve sustainable development, (Pedro, 2005). Wise and Shtylla (2007:14) reveal that, "inclusive business models such as those by British Petroleum in Trinidad and Tobago or by Anglo American in South Africa have moved beyond generating procurement opportunities for small and medium enterprises (SMEs) and are building local supply chains and complex capabilities". In Tanzania, De Beers has partnered with government, local NGOs, communities and development organisations to establish the Mwadini Community Diamond Partnership, (Wise and Shtylla, 2007). Wise and Shtylla (2007:13) advance that the aim of the initiative is to produce a viable and potentially transferable model for improving qualities of life in mining-based rural populations and exploring alternative livelihoods projects.

In early 2010, Anglo American mining giant implemented an empowerment programme aimed at empowering underprivileged individuals and promoting economic growth in South Africa's mining and laboursending communities, (Anglo American Case study, 2011:1). The document goes on to state that the company established a dedicated unit called Anglo Zimele, "to address key challenges to enterprise development and empowering in these communities". United Nations Economic and Social Council (2009:8) reveal that African ownership of mineral assets has increased because of Black Economic Empowerment (BEE) schemes. Local equity participation in mining projects has been promoted and embedded in to law in South Africa. Wise and Shtylla (2007:14) contend that, "Anglo American's Zimele programme aims to achieve large-scale impact by investing in and supporting black-owned and managed enterprises". Thus according to a survey conducted in 2005, more than $70 \%$ of the enterprises in which Zimele has invested have survived eight years or more.

The Impala Bafokeng Trust became the landmark of Black Economic Empowerment (BEE) transaction in 2007 between the Royal Bafokeng Nation (RBN) and Impala Platinum Holding limited (Implats), (IBT Annual Report, 2011). The Impala Bafokeng Trust's empowerment programme focuses on areas such as, education, health, enterprise development, capacity building as well sport and recreation. The Trust seeks to go beyond mere grant-making in any of these areas, its concern being to avoid duplication of effort but rather seeking to facilitate common purpose partnerships in which the private, not-for-profit and public sectors collaborate on specific programmes, The Impala Bafokeng Trust Annual Report (2011). Wise and Shtylla (2007), United Nations Economic and Social Council (2009) and the Anglo American Case study (2011) agree that mining companies can have greater impact when they develop inclusive business models that integrate local small-tomedium enterprises (SMEs) into their value chain, thus fostering local entrepreneurs. This article explores how local communities in Gwanda rural district in Zimbabwe could directly benefit from mineral resources in their areas. The case studies on Anglo-American's Zimele programme and the Impala Bafokeng Trust discuss effective community empowerment strategies which have been used in other countries and hence these give this article a regional and international flavour.

In Zimbabwe, Zimplats effectively set the ball rolling when President Mugabe launched the US \$10 million Mhondoro/Ngezi/Zvimba CSOT. Mimosa Mining Company and Unki Mine followed suite. The Community Share Ownership Trust was launched by the Government of Zimbabwe in order to empower indigenous Zimbabweans and to address imbalances spawned by colonial dispossession, (Maodza, 2012). Zimplats agreed to undertake several projects which will benefit the local community and the Zimplats Annual Report for 2010 indicates that US $\$ 10.58$ million had been allocated for social development projects in the next few years, (Matyzak, 2012). Saunders (2007:13) adds that the 2006 bilateral empowerment agreement with government saw Zimplats cede an undeveloped piece of ground equalling $36 \%$ of its total land claim to the state in exchange for indigenisation 'credits'. Also included in the deal were parts of Zimplats' built-in infrastructure, including $80 \mathrm{~km}$ of road, electricity supply, housing and social amenities for the mining communities on site, for which the company was given dollar-for-dollar credits, (Saunders, 2007).

\section{The Indigenisation and Economic Empowerment Act (General Regulation, 2010), Zimbabwe.}

The Indigenisation and Economic Empowerment Act (General) Regulation, 2010 section 3(1) of the Notice provides that:

Every non-indigenous mining business shall achieve the minimum indigenisation and empowerment quota by the disposal, after approval of its indigenisation implementation plan by the Minister, of its shares or interests to designated entities, (Matyzak, 2012). The General Notice 114/2011 requires that all mining businesses achieve indigenisation by disposing 10\% shares to a CSOT. Murombo (2010:584) contends that the Indigenisation and Economic Empowerment Act (IEE Act) provides that: 
It is the objective of the Government [of Zimbabwe] ---- to secure that-

(a) at least fifty-one percent of the share of every mining company which on or after the fixed date, is engaged in the extraction or exploitation of any one or more strategic energy minerals, shall be owned by the State, of which shares-

i. twenty-five per centum shall constitute the non-contributory interest of the State; and

ii. twenty-six per centum shall constitute the contributory interest of the State

(b) at least fifty-one per centum of the shares of every mining company which on or after the

fixed date, is engaged in the extraction or exploitation of any precious metals or precious stones, shall be owned by the State and indigenous Zimbabweans, of which shares-

i. twenty five per centum shall constitute the non-contributory interest of the State; and

ii. twenty six per centum shall be owned by the State or indigenous Zimbabweans;

(c) at least fifty-one per centum of the shares of every mining company which on or after the fixed date, is engaged in the extraction or exploitation of any mineral other than a strategic energy mineral, precious metals or precious stones, shall be owned by indigenous Zimbabweans.

Thus mining companies are expected to meet these requirements within fixed time frames, failing which the relevant Minister, depending on the reason for non-compliance, can cancel the mining right. The holder of the mining right is given an opportunity to have reasons for such a cancellation being made and has an opportunity to make written representations, (Murombo, 2010). Kanyenze et al (2011) add that those companies that did not surrender the initial 25 per cent to empowerment for free would be levied a tax of 25 per cent of the value of their production. In the event that no production was realized, the 25 per cent tax would be levied on the estimated value of reserves they would be likely to produce in a year.

\section{Community Share Ownership Trusts (CSOTs) in Zimbabwe.}

Mining laws must facilitate access to, and equitable sharing of benefits of mining. Since independence in 1980, Zimbabwe has lagged behind in terms of the establishment of an enabling legal and policy framework for sustainable and equitable mineral resource development. The country is now fast tracking the mining sector legislation which supports broad economic empowerment. Thus in 2007, government's approach to empowerment took a new direction in response to the changing political and economic environment, (Saunders, 2007). Murombo (2010:571) asks whether Zimbabwe's mining laws and the Indigenisation and Economic Empowerment Act (IEE Act) are suitably tailored to promote intra generational equity in the mining sector in Zimbabwe. The article views CSOTs as a countrywide government initiative spearheading development and empowering rural communities by giving them 10 percent stake in all businesses that exploit natural resources in their areas, (Maodza, 2012). He adds that the schemes are "designed to control the selfish exploitation of the country's resources for the benefit of multi-national corporations and other foreign businesses without benefit to indigenous Zimbabweans". The article reiterates that empowering communities in mining regions enables them to participate in their own development. However, Mate (2002:7) argues that the problem of informal diamond trade in Zimbabwe is exacerbated by the existence of a network of powerful political figures in whose interests is to maintain the illicit trade. Pedro (2005) expresses similar sentiment by revealing that Zimbabwe has seen the emergence of elite-driven, opportunistic asset grabs, rather than the articulation of a policy seeking the sustainable transfer of strategic production into accountable hands, (Saunders, 2007).

The Zimunya-Marange CSOT initiative which is provided for under section 14(b) of Statutory Instrument 21 of 2010 became the fifth after Mhondoro-Ngezi Trust in Mashonaland West Province, Gwanda Trust launched in Matabeleland South Province, the Zvishavane-Shurugwi Trust and the Tongogara Trust in Midlands Province, (Maodza, 2012). Maodza (2012:1) states that the CSOTs seek to create conditions that enhance the status of the people through the development of competitive domestic private sector partnership through establishment of bodies that will hold shares in qualifying business on behalf of their respective communities. The concept of CSOT is noble in that it is an opportunity for the locals to enjoy the proceeds of the mining operations in their areas while the resources are still there, (Maodza, 2012). The proclaimed objective of CSOTs is that the community in the district of a mining operation could reap some benefits from the exploitation of the natural resources in the area they inhabit. However concerns have been raised by some analysts (see Saunders, 2007 and Maodza, 2012) who felt the empowerment drive is only aimed at benefiting people in the mining areas at the expense of the entire populace.

Under the community share ownership scheme, companies operating in a given area cede a 10 per cent stake to the community and the money generated from the shareholding is then used to fund development projects such as building clinics, schools, roads and bridges, (Musarurwa,2012). Interviews conducted in 2012 with Chairman of the Gwanda CSOT, Chief Khulumani Mathema, revealed that the trust was planning to spend US \$1 million to complete work on Mapati, Silikwe and Sitezi clinics as well as rehabilitate Guyu and Chelesa irrigation schemes. Musarurwa (2012) also added that in Zvishavane the CSOT had funded the construction of two classroom blocks as well as rehabilitation of some roads. In Shurugwi, the trust was funding the 
construction of four classroom blocks at Musasa primary school, three teachers' houses, drilling of a borehole at the school and the construction of a maternity ward as well as a mortuary at Zvamabande hospital. The Marange-Zimunya CSOT was expected to implement infrastructure development projects following a US \$50 million pledge from five companies operating in the diamond fields. However the article argues that communities on their part should put in place mechanism to prevent abuse of trust funds. For instance, communities should not allow what happened in Zvishavane where chiefs are reported to have paid themselves US \$5 000.00 each as sitting allowances for the whole year from the trust fund. It is such abuse that will deny communities the benefits of trust funds, (Musarurwa, 2012).

Mate (2002:12) asserts that community participation in the management and use of mineral wealth at the local level "could speed up the process of community empowerment and lead to increased pressure on central government for better management of mineral wealth and for greater transparency and accountability in its management". Mate (2002) adds that most of the major mines had established foundations through which they are involved in the provision of health and education infrastructure as well as provision of non-mine training and education. For instance the Zimbabwe Platinum Mines agreed to transfer 51 per cent of its equity to indigenous investors in an empowerment deal where local communities will gain US \$600 million in value from the mining giant. Through its South African parent firm, Implats, Zimplats agreed to shed 10 per cent to local communities, 10 per cent to workers, and 31 per cent to the National Indigenisation and Economic Empowerment Fund, (Matyzak, 2012).

According to Maodza (2012:3) the Zimunya-Marange share ownership programme became unique in that the trust was given mining rights and will partner with companies operating in the diamond fields. The new approach has a multiplier effect on the benefits to be accrued by communities in that they will benefit from value retention through direct ownership of mining concessions. This enables communities to fully participate in the economic spheres that surround them. Similarly the Zimplats Holding has agreed to a vendor finance deal, whereby it will provide an interest free loan to the Community Share Ownership Trust to fund the purchase of the issued shares, valued independently and the loan will be repaid from dividends, (Matyzak 2012). However the shareholding granted to the CSOT will not, in this event, render the community any better off financially. Accordingly, channelling money for development projects through the CSOT in the form of dividends, rather than grants, merely allows for some expedient public relations and politicking, and does nothing to advance community empowerment, (Matyzak, 2012). Furthermore without general restrictions as to who may purchase and who may sell shares, the $10 \%$ indigenisation through schemes such as the CSOT may be quickly reversed, either through onward selling or a call upon collateral,( Matyzak, 2012).

\section{The Research Design}

\section{Methods}

The descriptive survey was used as a research design. The study followed an exploratory approach whereby the strategies of harnessing mineral resources for social and economic empowerment of local communities were explored

Data collection tools such as questionnaires, document reviews, and key informant interviews were used in the study to collect data. The combination of these methods was done to reduce the effect of the weaknesses of each method selected. For instance the questionnaire and documents reviews revealed the trends, while the key informant interviews explained the trends and gave in-depth data.

\section{Population and Sampling}

The mines in Gwanda Rural District Council (GRDC), sector ministries, the wards and villages situated close to the mines, constituted the population of the study. This study targeted the mining companies, local communities close to the mining companies, the Ministry of Mines, Ministry of Youth Development, Indigenisation and Empowerment, Environmental Management Agency (EMA) and GRDC and the District Administrator's office. The list of mines in Gwanda district, the list of wards and list of villages in these wards was used as a sampling frame for the study. The sampling frame was obtained from the GRDC, sector ministries and the mining sector in Gwanda district. The sample size was a total of 50 respondents. The sample consisted of 30 research participants from the local community, 10 key officials from the GRDC and the DA's office, 5 key stakeholders from the mining companies and 5 key informants from the other stakeholders such as the sector ministries. The study used a simple random sampling and purposive sampling designs.

\section{Results and Discussion}

This article discusses the results of the research in the context of the following objectives:

- To examine the mining policies and legislative frameworks which are aimed at socially and economically empowering the indigenous communities.

- To analyse the Zimbabwe's economic and social empowerment strategy for sustainable development. 
- To assess how mineral resources could be harnessed to enhance community empowerment, poverty reduction and infrastructure development.

- $\quad$ To analyse the extent to which mining has directly benefitted the local communities.

\section{Mining Policies and Legislative Frameworks on Social and Economic Empowerment}

On being asked whether Zimbabwe policy makers had enacted pro-poor policies that empower the local indigenous communities, the respondents reacted as reflected in figure 1 below.

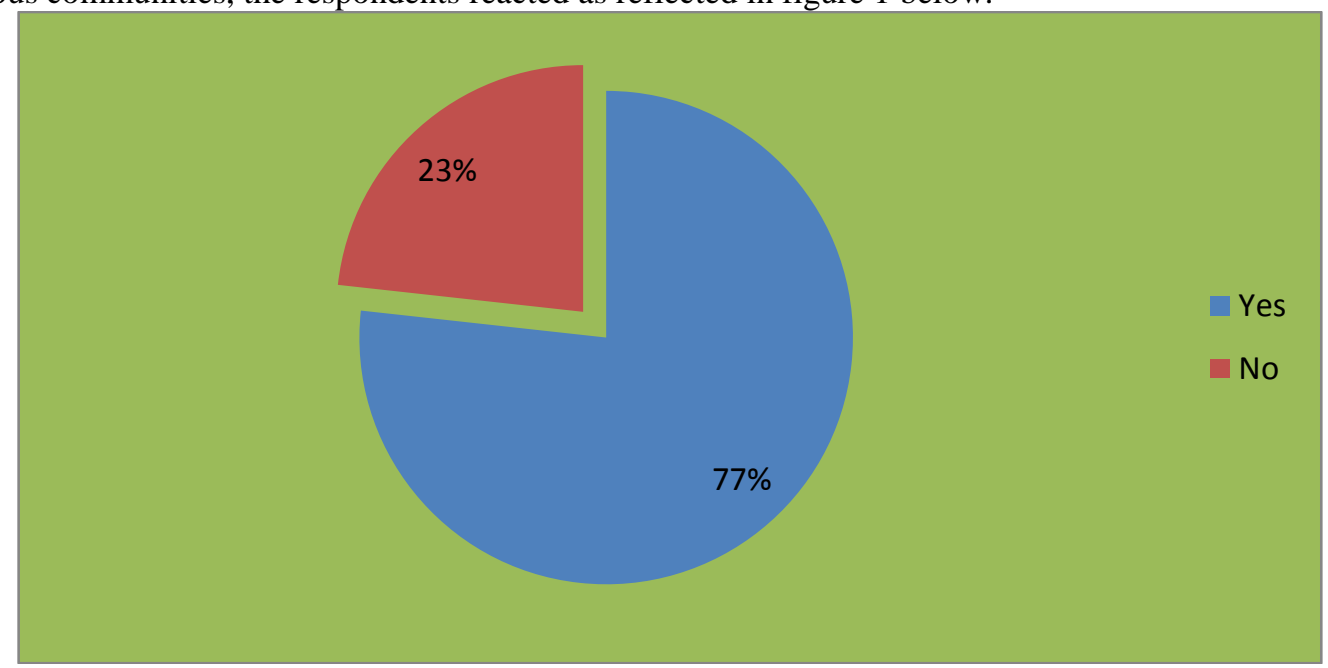

Figure 1: Formulation of Pro-poor mining policies in Zimbabwe

Seventy-seven percent (77\%) of the respondents agreed that Zimbabwean policy makers have formulated propoor mining policies that could ensure empowerment of the local indigenous communities. However $30 \%$ opposed the view. It would appear that the majority of the respondents identified the Indigenisation and Economic Empowerment Act (IEE Act) and a statutory instrument for Community Share Ownership Trust (CSOT) as pro-poor policies which can enhance social and economic empowerment of the local communities. Further probing of the respondents seemed to confirm the results above. Most of the respondents interviewed seemed to advance the view that the current mining legislation had improved the lives of the local communities. The GRDC official stated that the Indigenisation and Economic Empowerment Act and the CSOT framework has:

"helped the GRDC to carry out community projects which include the completion of Guyu-Chelesa irrigation scheme, construction of Sitezi and Mapate clinics, road construction, construction of Silikwe clinic and fencing of Sibhula secondary school",(Interview,18/01/2012).

The evidence from the field seemed to be consistent with the earlier findings by the Economic Commission for Africa (2011) which advanced that the effective harnessing of mineral revenue for economic and social empowerment calls for the design of national policy frameworks focusing on socio-economic development and poverty alleviation. However, the minority of the respondents who opposed the view felt that the current legislation is not harmonized with the RDC Act, EMA Act and Mines and Minerals Act. Lack of a conducive political and economic climate was identified as the challenge which had inhibited the Zimbabwe legislators from formulating pro-poor policies which can empower local communities.

The article argues that current indigenisation and empowerment pro-poor policies such as the (IEE Act) and the CSOT Statutory Instrument 21 of 2010 were a progressive effort to empower the communities in Zimbabwe. If well implemented these policies could improve the lives of the local communities. The challenge facing the effective implementation of indigenisation and empowerment legislation in Zimbabwe is the problem of institutional capacity to implement these policies. It is imperative to acknowledge that while policies are well thought out and necessary, the other challenge is that of corruption and elite capture which could repeat the land reform fiasco where there was indiscriminate land grab. However in this case it will be mine grab and mineral looting. This is confirmed by Saunders (2007:18) who argued that, "Zimbabwe has seen the emergence of elitedriven, opportunistic asset grabs, rather than the articulation of a policy seeking the sustainable transfer of strategic production into accountable hands". Thus the indigenisation and empowerment legislation is important but the problem is that during the actual implementation of the policy, the politically connected elite benefit at the expense of the local communities. However Botswana (, (O'Connell and Lindsay, 2011) has used mining policies to empower its citizens without major challenges. The article adds that Zimbabwe can also achieve total empowerment if political will is entrenched. 


\section{Policies Benefiting Indigenous Local Communities}

In the wards that were targeted, communities perceived that mining policies must create conditions which allow local indigenous communities to benefit from mining activities in their areas. Pro-poor and democratic policies must ensure communities benefit from mining activities. Figure 2 reflects the views of the respondents on the need for the government to ensure that mining policies enable local communities benefit from mining activities.

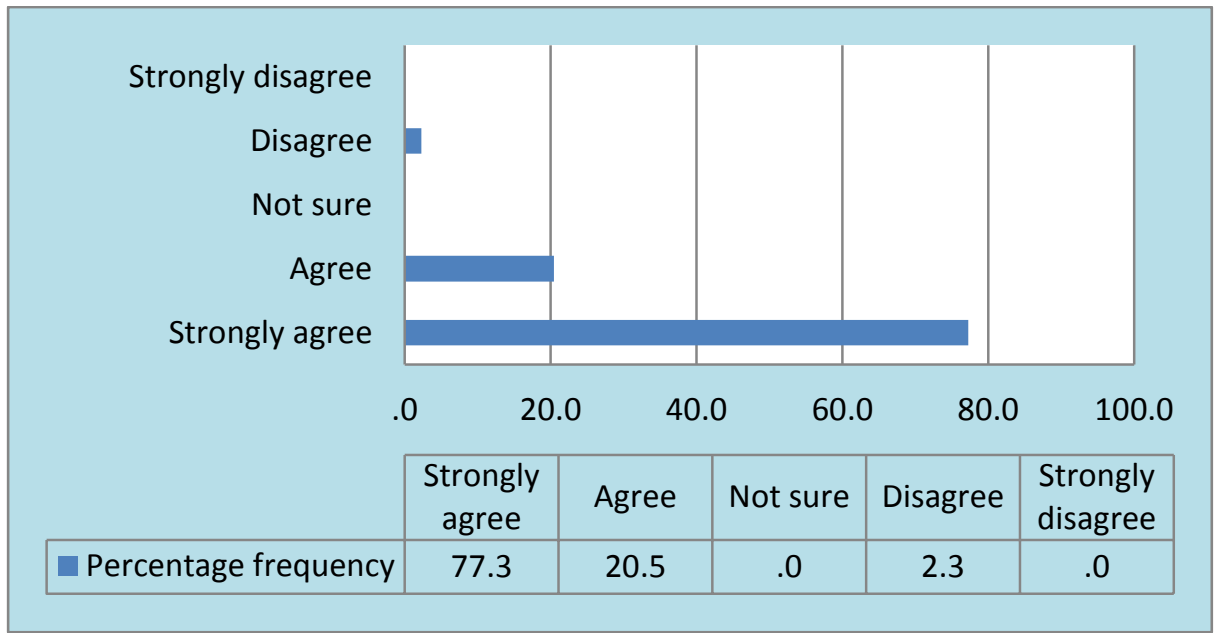

Figure 2: Policies benefiting indigenous local communities

Twenty- one percent $(21 \%)$ of the respondents supported the view that mining policies must ensure that indigenous local communities, who are the owners of the land where mines are located, benefit from the mining activities. Seventy-seven percent (77\%) advanced similar sentiments and strongly stated the need for mining legislation which ensured local indigenous communities benefit from mineral resources. Two percent $(2 \%)$ of the respondents opposed the view that policies must ensure that indigenous communities benefit from mining activities. The Key informants revealed that the IEE Act and a Statutory Instrument for CSOTs have been instrumental in helping local communities in Zimbabwe to benefit from the mineral resources. A Ministry of Mines official stated that:

"although the indigenisation legislation is a progressive step towards social and economic empowerment, the legislation need to be harmonized with the RDC Act, Minerals and Mines Act, Forestry Act and the Communal Lands Management Act if empowerment can be a broad based legislative framework", (Interview, 18/01/2012).

The results from figure 2 above suggest that the majority of the respondents strongly supported the view that mining policies must ensure that local communities benefit from the mining activities. These results are consistent with sentiments expressed by Murombo (2010) and Kanyenze, Kondo, Chitambara and Martens (2010) who declared that mining laws must facilitate access to, and equitable sharing of benefits of mining. Kanyenze et al (2010) expressed that Zimbabwe could benefit from policies that allow broad-based economic empowerment and the distribution of wealth to empower the indigenous people.

In related studies, Frucs and Agba (2007) and Bryan and Hofmann (2007) advanced that the governments have to implement a policy framework to ensure mineral wealth is captured and creates a long lasting benefit for local community and population and maximise ' value-added' from mineral extraction. Frucs and Agba (2007), Bryan and Hofmann (2007), Murombo (2010) and Kanyenze et al (2010)'s findings seem to converge with the results in figure 2. The key informants felt that the provision of appropriate legal and policy frameworks, together with adequate level of political stability would attract foreign investors who could help to stimulate investments and create employment opportunities for the people of Gwanda Rural District. However, the EMA official stated that:

"Investors must give back to the local communities where they are extracting mineral resources and establish effective environmental management and social protection programmes" (Interview, 18/01/2012).

It is true that the provision of appropriate legal and policy frameworks, together with adequate level of political stability would attract foreign investors who could help to stimulate investments and create employment opportunities for the people of GRDC. The challenge is that politicization of the indigenisation and empowerment policies might scare away prospective investors, restrict the foreign direct investment (FDI), reduce production levels in the mining sector and subsequently weaken and compromise the Corporate Social Responsibility programmes and the CSOTs. CSOTs can kill the FDI and the withdrawal of FDI will automatically destroy CSOTs in Zimbabwe. The CSOT Statutory Instrument 21 of 2010 was a noble move; however one would question the wisdom of creating a parallel taxation structure when there is the RDC mining royalties. One would have expected that the RDC royalties would be reformed and rates improved instead of 
establishing a completely new mechanism of harnessing mineral revenue. The current scenario has created a double taxation regime that is the COST and RDC mining royalty.

The article argues that in order for rural communities to experience meaningful empowerment, the CSOTs must focus on entrepreneurial projects which are focused on creation of employment opportunities for the rural unemployed youth. Observation on the ground show that there is collective empowerment of the community through infrastructure projects rather than individual empowerment. The improvement of the community infrastructure such as schools, roads, clinics and bridges is important and is a responsibility of the RDC and State agencies. One would argue that there is need for the government to harness mineral resources for the total empowerment of members of the community as individuals, since Zimbabwe is characterised by high levels of unemployment.

\section{Mining Contributions to the People of Gwanda Rural District}

Development practitioners believe that mining policies and legislative frameworks must ensure that mining activities embrace broader development goals such as infrastructure, agriculture and forestry. Responding to the question based on what the mining companies have contributed to people of Gwanda District, the respondents reacted as shown on figure 3 .

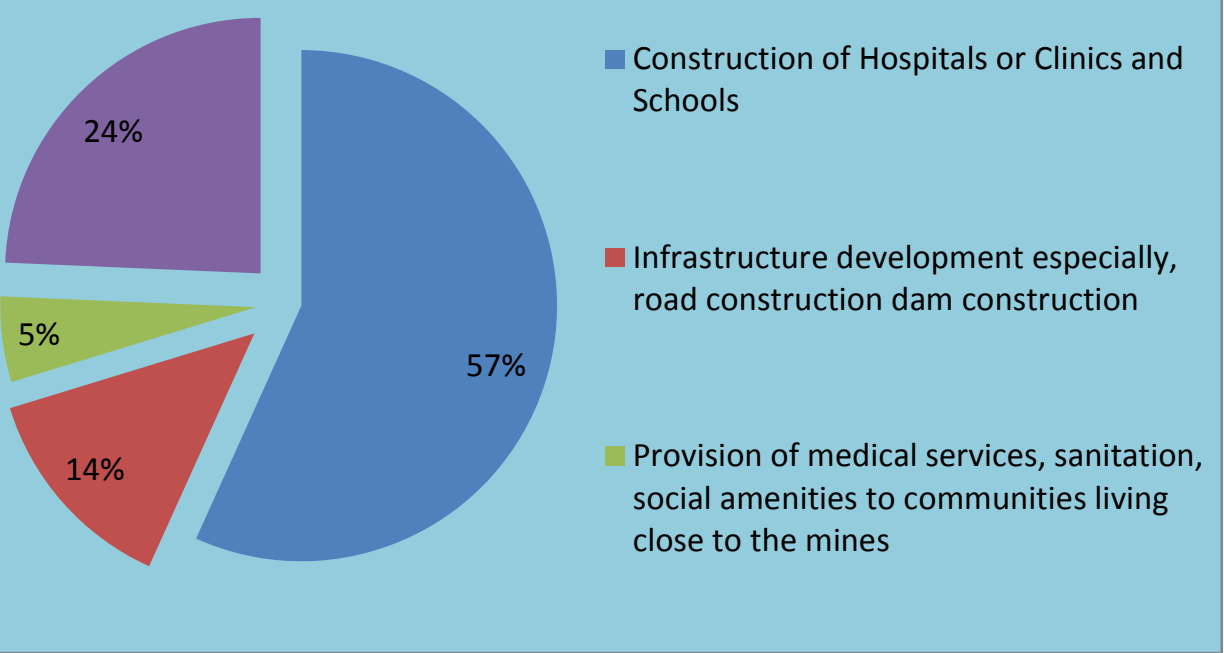

Figure 3: Mining contributions made to the people of Gwanda Rural District

Figure 3 indicate that $57 \%$ of the respondents revealed that construction of hospitals or clinics and schools were some of the projects undertaken by the mining companies in Gwanda Rural District Council (GRDC). Twentyfour percent of the respondents revealed that mining companies helped through the creation of employment opportunities, funding SMEs, provision of electricity, water, improving of housing and provision of transport for the local community. Fourteen percent (14\%) of the respondents advanced that mining companies contributed towards the development of GRDC through infrastructure development especially road construction and dam construction. Only 5\% of the respondents identified the provision of medical services, sanitation, social amenities to communities living close to the mines as some of the contributions made by the mines.

The evidence from the field suggest that the mining companies operating in GRDC have harnessed mineral resources and implemented various projects focused on infrastructure development in transport, education, energy, health, water, sanitation and hygiene (WASH) and social amenities. Creation of employment opportunities and funding of small and medium enterprises (SMEs) were some projects identified by the respondents. The article argues that employment creation through establishment and funding of local economic development projects is the answer to poverty reduction and realistic empowerment of rural unemployment. The key Informants also confirmed the results in figure 3 above. The GRDC senior official stated that:

"the mines have constructed primary and secondary schools in areas where they operate, for instance Collen Bawn mine constructed a school and handed it over to local government", (Interview, 18/01/2012).

These results seemed to be consistent with earlier findings by the United Nations Economic Commission for Africa (2011) which proclaimed that there is an emergent realization that mining could be a key instrument in establishing infrastructure (transport, energy and water) for development of other sectors, such as agriculture and forestry. Weber-Fahr, Strongman, Kunanayagam, and Sheldon (2001:8) also found that mining companies have provided substantial additional employment opportunities and investments in basic public infrastructure, goods and services with universal access, for example transport, water and power. Weber-Fahr et al (2001), Bryan and Hofmann (2007) and the results in figure 3 seemed to dispute the assumption of the mineral resource curse theory and advance the view that mineral resources are a blessing and not a curse. 
Although some analysts believe that Corporate Social Responsibility (CSR) must be made legally mandatory, the article disputes the view. The article argues that If CSR initiatives are made legally mandatory in Zimbabwe, the Community Share Ownership Trusts will be irrelevant in the current situation. The concept of CSOTs and CSR are congruent hence the mines might view this development as double taxation on their part. If these two programmes run concurrently in Zimbabwe, then the country needs to establish an investor friendly investment and political climate in order to attract FDI to the mining sector. Reliance on CSR for community empowerment could be a challenge because the scale and nature of CSR activities will vary at different stages of mining from exploration to closure. Effective CSR initiatives are based on long-term dialogue with the community, however such dialogue depends on strong rural community leadership which may not be easy to establish.

\section{Social and Economic Empowerment Strategies}

There are various strategies which can be implemented by governments in order to empower local communities socially and economically. Respondents' perception on the strategies which can be used to socially and economically empower local communities in Zimbabwe is shown in table 1 below.

Table 1: A list of social and economic community empowerment strategies

\begin{tabular}{|l|l|}
\hline Social Empowerment focal foundations to fund and drive & $\begin{array}{l}\text { 1. Equity share arrangement and making corporate } \\
\text { social responsibility mandatory. }\end{array}$ \\
\hline $\begin{array}{l}\text { 1.Establishment of lowpowerment } \\
\text { 2.Community Share Ownership Scheme/Trusts }\end{array}$ & 2. Public-Private Partnership arrangements \\
\hline 3. Cash transfers & 3.Revenue sharing schemes \\
\hline 4. Mining royalties & 4. Mining taxes/ rents \\
\hline 5. Social and environment fund & 5. Bonds and Insurance payments \\
\hline
\end{tabular}

The respondents identified the Indigenisation and Economic Empowerment Act and the CSOTs as the major strategies which are currently adopted by the Zimbabwean government. The Gwanda Rural District official stated that:

"if mineral profits are paid directly to the Community Share Ownership Trust, then the local authorities can easily implement community based development projects" (Interview, 18/01/2012).

However the respondents felt that the Government, Rural District Councils (RDCs) and the Mines must establish a forum where they can engage and agree on key community empowerment projects. The district official in the Ministry of Youth stated that:

"revenue from mining must be used to establish a district empowerment revolving fund which provides low interest to indigenous people to initiate small and medium enterprises in agriculture, construction and commerce”, (Interview,18/01/2012).

The provincial official of the Ministry of Youth added that:

"there must be qualified mentors experienced in entrepreneurship, project management and community development to mentor and monitor the small and medium scale enterprises”. (Interview, 18/01/2012).

Thus the article reiterates that CSOTs must be used as vehicle of employment creation and empowerment of rural communities and not just for community based infrastructural development. However this article emphasises that transparency and accountability mechanisms must be established to prevent corrupt practices and ensure that the CSOTs gain credibility within Mines, the Government and community of Gwanda Rural District.

It is important that CSOTs fit with RDC's strategic plans and development objectives and the CSOT frameworks and management should not create parallel structures. The CSOTs should harness development plans of the local authorities if transparency and accountability mechanisms can get a legal base to prevent corrupt practices from the CSOTs board members.

\section{Sharing of Mining Revenue between the Local Authorities and Local Communities}

Sharing of mineral revenue between the RDCs and local communities is a new concept in Zimbabwe. Mines have been paying royalties to the RDCs but the communities have not benefited much. However the current context in Zimbabwe aims to change mining landscape and improve the benefits to the communities living in mining areas. Survey results painted an interesting picture in this era of social transformation and community empowerment. The research believes that the CSOTs can enhance the empowerment of communities; the view is reflected in figure 4. 


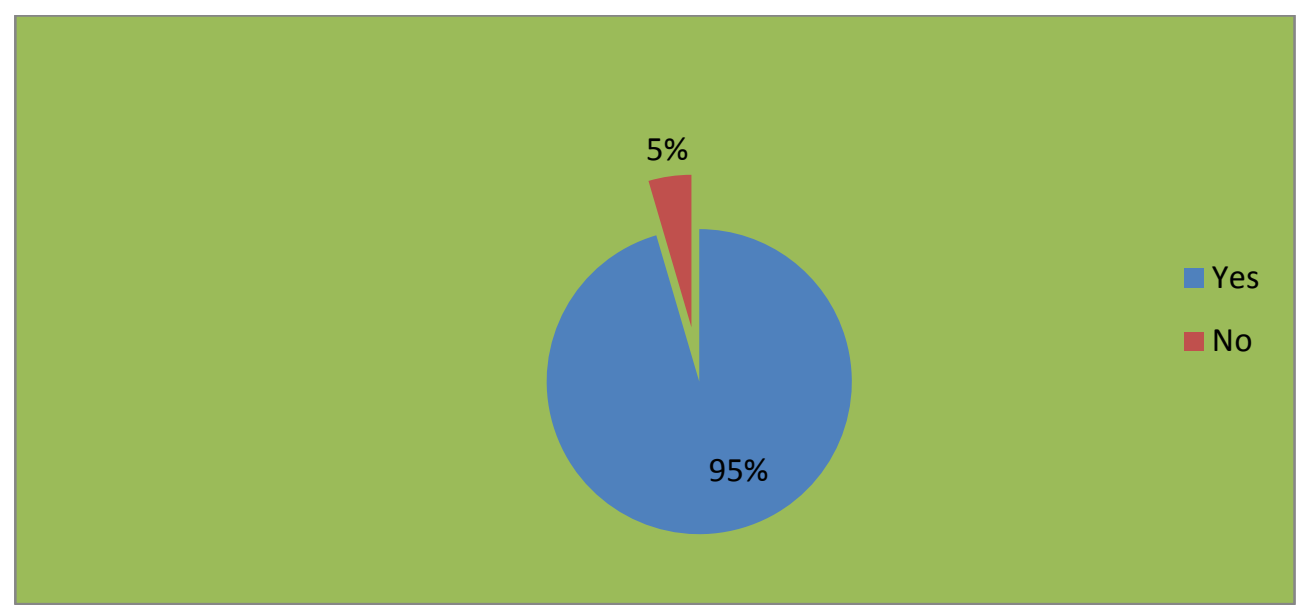

Figure 4: Sharing of mining revenue between the local authorities and local communities

Ninety-five percent of the respondents supported the view that revenue sharing with local authorities through the CSOTs could enhance the empowerment of local communities. Only five per cent opposed the view. The results suggested that the communities have been capacitated through community mobilisation and awareness programmes on the significance of mineral resources and the revenue accruing from them. These results seemed to suggest that communities around mining areas have a newly found sense of entitlement and were now demanding economic benefits. These results are consistent with findings by the United Nations Economic and Social Council (2009) which found that revenue sharing with communities and local authorities had slowly been increasing in Ghana, Sierra Leone and South Africa which have already implemented revenue sharing schemes between local authorities and local communities. For instance the Anglo-American's Zimele and the Impala Bafokeng Trust are good models which can be adopted by Zimbabwe.

The article accepts the view that revenue sharing with local authorities through the CSOTs could enhance the empowerment of local communities. The Campfire programme runs under the auspices of the RDC, however for the CSOTs, why is the government creating a parallel structure when the Campfire structure is still functional. The other question to ask is why are mines obligated to direct the revenue directly to communities who are land occupiers when the land holder (RDC) is just a partner in the CSOTs administrative structure.

\section{Mechanism of Mineral Revenue Sharing in Gwanda Rural District Council and Local Communities}

There are various mechanisms for sharing mineral revenue between the local authorities and the local communities affected by mining activities. The respondents portrayed their preferred mechanisms as reflected in table 2 below.

Table 2: Mechanism for sharing mineral revenue between the Gwanda RDC and local communities

\begin{tabular}{|ll|r|r|}
\hline \multicolumn{2}{|c|}{ Response } & \multicolumn{1}{|c|}{ Frequency } & Valid Percent \\
\hline Valid & Mineral profits directly paid to community & 24 & 68.6 \\
& share ownership scheme & & \\
& Rural district council's royalty and mining & & 22.9 \\
& taxes paid by the mining companies & & \\
& Company taxes & 3 & 8.6 \\
& Total & 35 & 100.0 \\
Missing & System & 9 & \\
Total & & 44 & \\
\hline
\end{tabular}

Sixty-eight percent of the respondents revealed that they preferred that mineral profits should be paid directly to community share ownership trust account. They felt that CSOTs were the best mechanisms for sharing mineral revenue between the Gwanda RDC and the local communities. Twenty-three percent (23\%) of the respondents preferred sharing revenue from the rural district council's royalty and mining taxes paid by mining companies. Nine percent (9\%) felt that proceeds from mining company taxes could be used as a mechanism for sharing revenue between the GRDC and local communities. The results suggested that community members who participated in the study could have been capacitated on the merits of CSOTs and the RDC mineral royalties which are paid by the company. As a result most of the respondents selected the CSOT and mineral royalties because these concepts have been widely publicized in the print and electronic media. Furthermore the respondents have seen the benefits of the CSOTs through the implementation of projects coordinated by CSOT 
committee and the RDC officials. The article argues that if these revenue sharing mechanisms are to be effective, there must be an open dialogue between government, mining companies, RDCs and local communities to deal with the problem of multiple taxation. For instance, in Zimbabwe there are royalties, CSOTs, Company tax, CSR and other mining rents which have to be borne by the mining investors. The article asserts that to bring sanity in the Zimbabwe mining sector, there must be harmonization of the tax regimes and provision of friendly legislative frameworks which can attract foreign investors.

\section{Responsibilities of Holders of Mineral Rights to Communities where they operate}

Advocates of community empowerment believe that the process of approving mining permits and licence must involve protocols of ensuring direct and indirect benefit to the local communities affected by mining. Communities in the wards visited have shown that mineral rights holders have a responsibility to the communities where they are extracting mineral resources. Figure 5 below gives a graphical position of the respondents on the statement that holders of mining rights must contribute towards the socio-economic development of the area in which they operate.

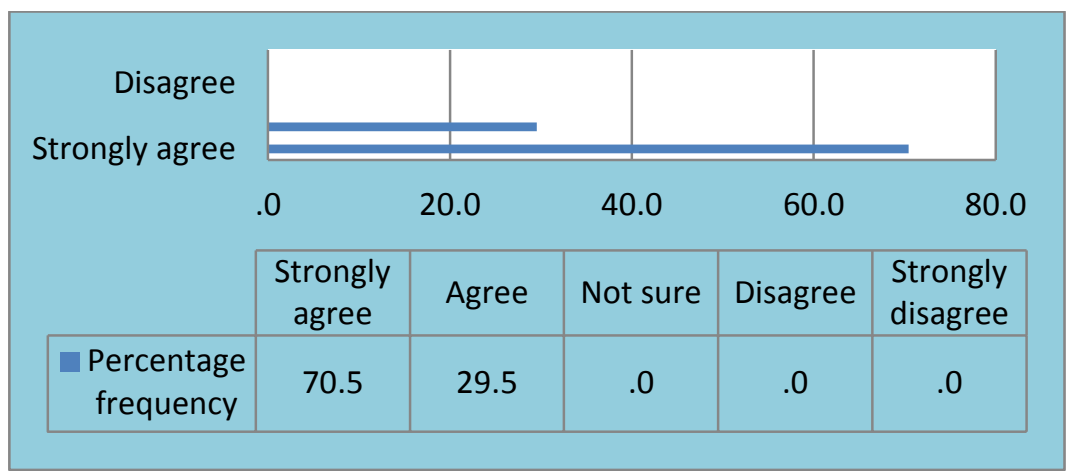

Figure 5: Responsibilities of holders of mineral rights to communities where they operate

Seventy-one percent $(71 \%)$ of the respondents supported the view that holders of mining rights must contribute towards the socio-economic development of the area in which they operate. Similarly $30 \%$ of the respondents held the same view. These results suggest that communities want to be involved in the process of granting of mineral permits and licences in order to ensure that the environment is protected and the communities benefit from mineral resources in their area. Murombo (2010) warns that once the mining company has secured the required permits and licences, there is no guarantee that the local communities would share the benefits. Thus the article argues that mineral rights holders must contribute towards the socio-economic development of the area in which they operate. These views are in harmony with findings by Mate (2002) who noted that company responses to community demands have included payments to community environmental protection funds, development of amenities, developing community projects in association with local governments and establishing foundations into which they pay sums to be used for community development.

Field observation of rural areas close to mines in GRDC centre shows a scenario of an island of development in a sea of underdevelopment. The rural areas around the mines do not show any evidence of development. The state of many roads is poor even those leading to the mines are not pleasing at all and there is no electricity in the rural communities. Perhaps this explains the new government stance of actually legislating CSOTs to try and compel mining companies to improve infrastructure in areas where they operate. The respondents identified responsible environmental management as another area which mining companies have to consider when extracting mineral resources from the land

\section{Harnessing Mineral Resources for Community Empowerment, Poverty Reduction and Infrastructure Development}

Harnessing mineral resources for community empowerment, poverty reduction and infrastructure development should be the main focus of any mining activity in Zimbabwe. Communities who participated in the study noted that mining could improve rural livelihoods and stimulate entrepreneurship in communities living close to the mines. Respondents identified ways in which mining can be harnessed to improve rural livelihoods and stimulate entrepreneurship. These ways are graphically shown in Figure 6 below. 


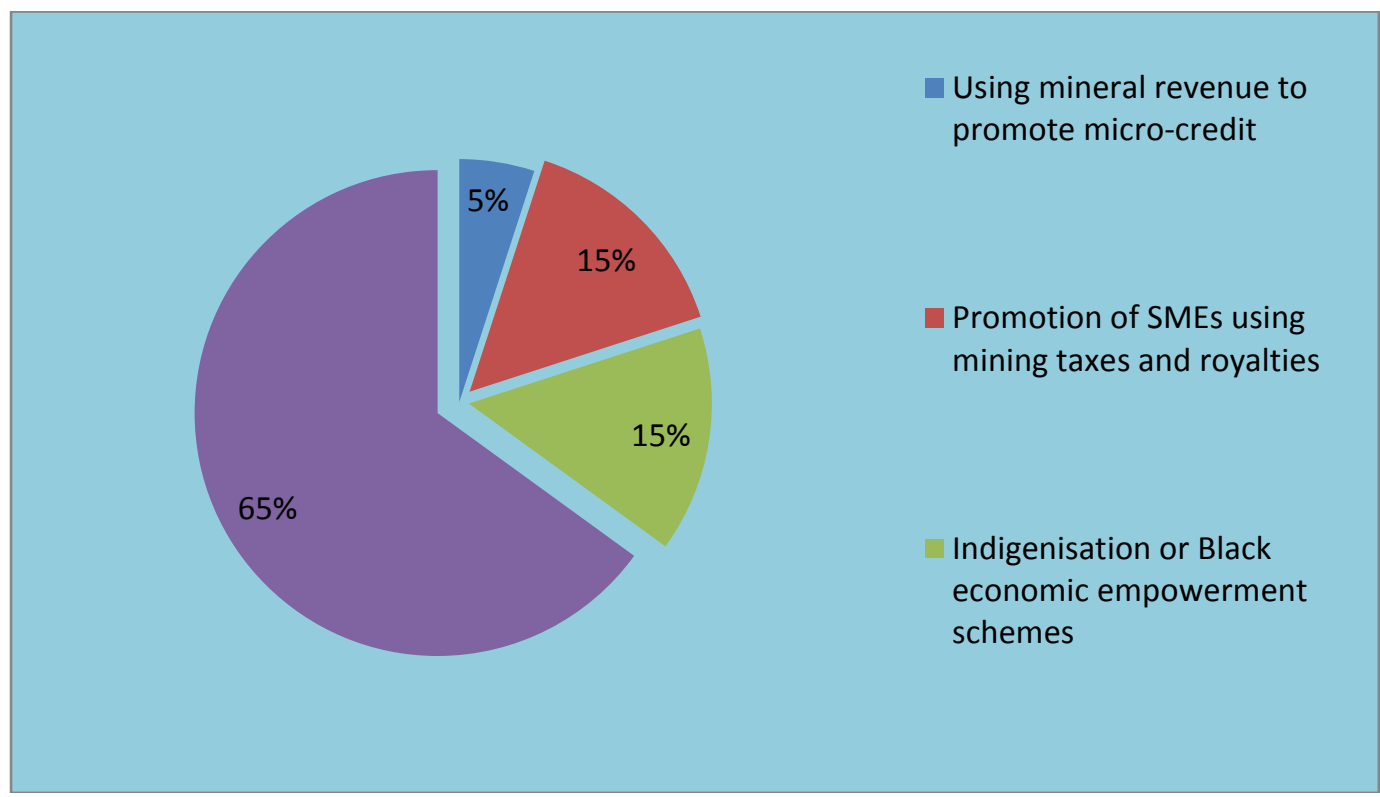

Figure 6: Harnessing mineral resources to improve rural livelihoods and stimulate entrepreneurship.

Sixty-five percent $(65 \%)$ of the respondents indicated that harnessing mineral resources to improve rural livelihoods and stimulate entrepreneurship can be achieved through infrastructure development especially houses, schools, hospitals, clinics, roads and provision of electricity and water. Surprisingly $15 \%$ of the respondents identified indigenisation or Black Economic Empowerment Scheme as a strategy of harnessing mineral resources to improve rural livelihoods and stimulate entrepreneurship in communities living close to the mines. Similarly $15 \%$ of the respondents cited the promotion of small and medium enterprises (SMEs) using mining taxes and royalties. Only $5 \%$ of the respondents identified the use of mineral revenue to promote microcredit as the strategy of harnessing mineral resources to improve rural livelihoods and stimulate entrepreneurship. These results suggest that communities viewed the development of infrastructure and provision of public utilities such as electricity and water, establishing micro-credit to small and medium enterprises (SMEs) and implementing broad-based indigenisation policies as strategies of improving rural livelihoods and stimulating entrepreneurship in communities living close to the mines.

The article argues that revenue from mineral production could aid poverty alleviation and increase economic development in rural areas. Frucs and Agba (2007:14) argued that mineral resources can be harnessed to improve livelihoods and stimulate enterprises through poverty reduction, employment generation, wealth creation and value re-orientation within the country. Andres Mejia (2011) also noted that mining can contribute to local economic development through investments which in turn enable better social services and catalyze improvements in physical infrastructure. The challenge of harnessing mineral resources for community empowerment in Gwanda rural is that projects implemented tend to be biased towards the development of community infrastructure rather than on SMEs which can promote employment and local economic development in rural areas. The article argues that for total economic empowerment to be realised in Zimbabwe, particularly in Gwanda rural district, a revolving fund for funding SMEs and local economic development must be established and managed transparently.

\section{Using Mining Revenue as an engine for Economic Growth and Financing Poverty Reduction Programmes.}

The effective harnessing of mineral revenue for social and economic empowerment, economic growth and poverty reduction marks a new era in the Zimbabwean political landscape. It can be argued that obtaining an adequate share of mineral revenue and utilizing it in an equitable manner is crucial for the success of the indigenisation drive and general economic development of Zimbabwe. Figure 7 reflects the views of the communities on whether government can utilize mining revenue as an engine of economic growth and poverty reduction. 


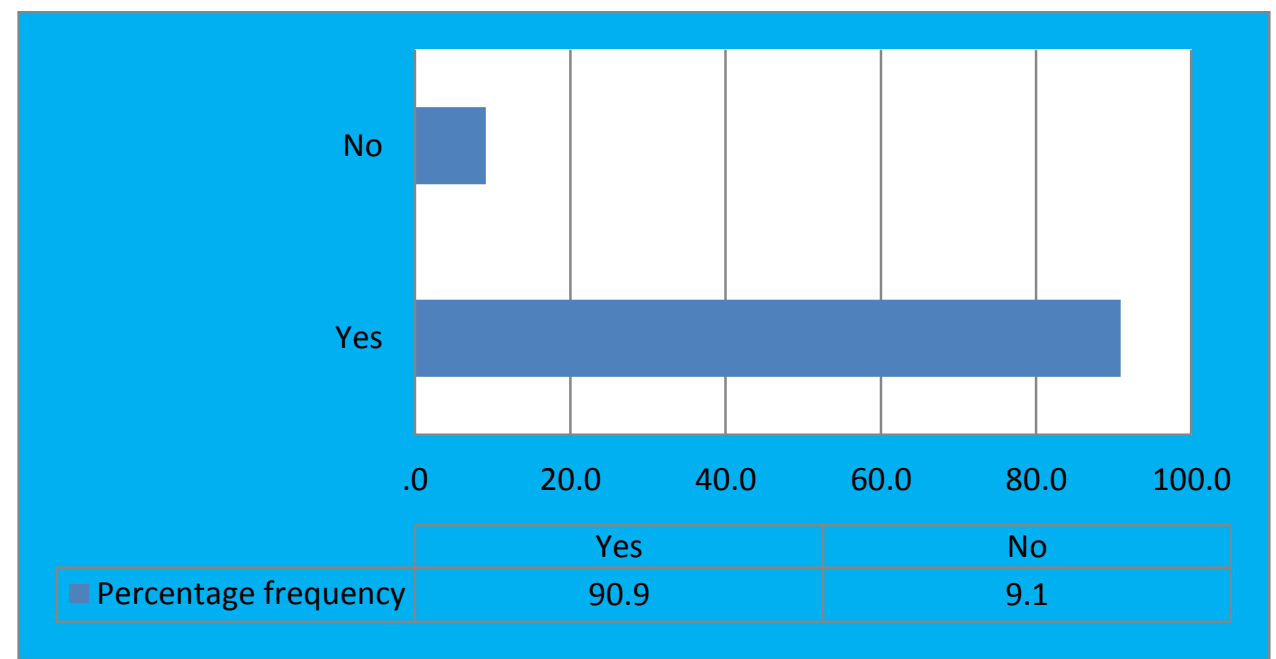

Figure 7: Using mining revenue as an engine for economic growth and financing poverty reduction programmes

Ninety-one percent (91\%) of the respondents supported the view that governments can use mining revenue as an engine for economic growth and a source of financing social services and poverty reduction programmes. However, just slightly above $9 \%$ of the respondents opposed the view. These results suggest that communities appreciate the importance of mineral revenue in economic development. Communities noted that the government can utilise mining revenue to stimulate economic growth and reduce poverty through CSOTs. These results are similar to the findings by Bryan and Hofmann (2007:15) who revealed that "revenues from mineral wealth could help alleviate poverty and spur development in many countries. Botswana is widely perceived as a model of the successful management of natural resources for development". In a similar study Martin and Taylor (2012:5) noted that if mineral wealth is managed right, "it could be the transformational vehicle through which the country can turn around its failing economic fortunes, while also serving as an example to other African countries blessed with mineral riches". Thus using CSOTs to harness mineral resources for social and economic empowerment depends on the effective management and distribution of mining revenue.

\section{Local Community Benefits from Community Share Ownership Scheme/Trusts}

The communities who participated in the study noted that the empowerment and indigenisation law was a recent attempt to ensure that local communities can share the benefits from mining activities. On being asked whether their communities have directly benefited from the CSOTs, respondents reacted as shown in figure 8 below.

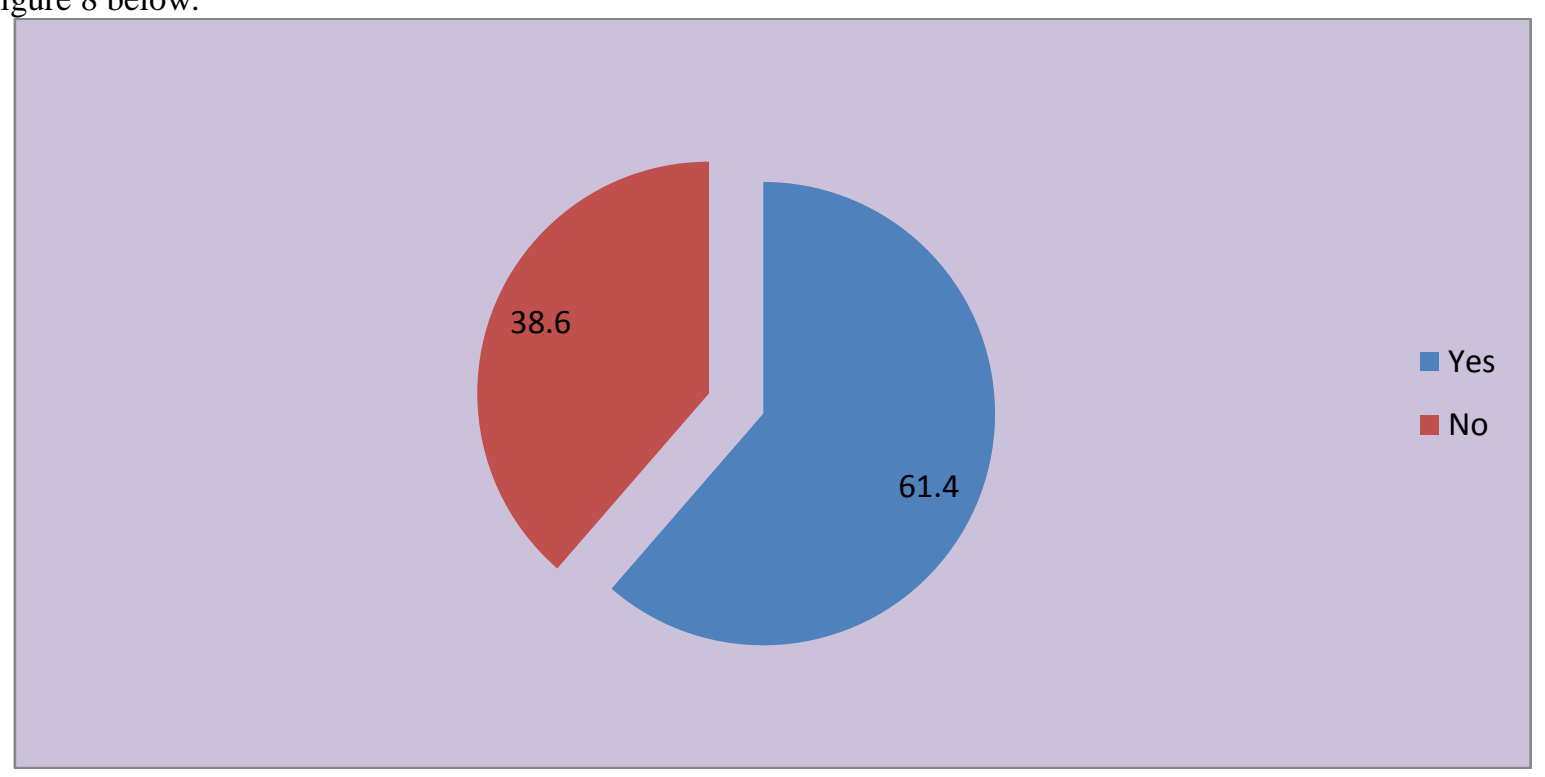

Figure 9: Local community benefits from community share ownership scheme

Figure 8 indicates that $61 \%$ of the respondents stated that their local communities have benefited from the CSOTs. However about $39 \%$ of the respondents stated that their communities have not benefited from the CSOTs. The results indicate that some communities have directly benefited from the CSOTs, although the 
scheme was recently launched in Gwanda Rural District. On further probing the respondents identified the specific projects which have been funded by the CSOTs in Gwanda Rural District. These include the completion of Guyu-Chelesa irrigation scheme, construction of Sitezi and Mapate clinics, construction of roads, construction of Silikwe clinic and fencing of Sibhula secondary school.

In a related study, Matyzak (2012:15) advanced that Zimplats had allocated US \$10.58 million to the CSOT for social development projects focused on community benefits. In Shurugwi the CSOT has funded the construction of four classroom blocks at Musasa primary school, three teachers' houses, drilling of a borehole at the school, and the construction of a maternity ward as well as a mortuary at Zvamabande hospital,(Musarurwa, 2012). The challenge to the mainstreaming of the CSOTs into the RDC development programmes and structures is the hidden political hand which may manipulate a truly developmental programme and turn it into political campaign tool. Cases of elite capture such has been raised by Saunders (2007:9) who declared that "Zimbabwe has seen the emergence of elite -driven, opportunistic asset grabs".

\section{Conclusion and Policy Recommendations}

The study concluded that the Indigenous and Economic Empowerment Act and the Statutory Instrument 21 of 2010, for Community Share Ownership Trust (CSOT) in Gwanda district were the pro-poor mining policies that propelled the effective harnessing of mineral resources for the empowerment of local indigenous communities.

Current trends indicated that the Amended Mines and Minerals Act, the Indigenisation and Economic Empowerment Act and the Statutory Instrument for Community Share Ownership Trust provided a legislative framework for corporate social accountability and responsibility initiatives in Zimbabwe. The research for this article indicated that holders of mineral rights must be compelled to contribute to socio-economic development of the area in which they operate. Therefore the article concludes that mining companies operating in Gwanda Rural District have harnessed the mineral resources and implemented projects focused on infrastructure development in transport, education, energy, health, water, sanitation and hygiene (WASH) and social amenities.

The Economic Indigenisation and the Community Share Ownership Trusts were viewed by the community as the major strategies which have been currently adopted by the Zimbabwean government. Current trends in Gwanda Rural District indicated that the Community Share Ownership Trusts were the best mechanism for sharing mineral revenue between the Gwanda RDC and the local communities. However some community members expressed that mining revenue must be used to establish a district community empowerment revolving fund which attracts low interest. The fund is expected to help local people of Gwanda Rural district initiate small and medium scale enterprises in order to create employment for the youth.

The article further concludes that the development of infrastructure and provision of public utilities such as electricity, water, establishing micro-credit to SMEs and implementing broad-based indigenisation policies are some of the strategies of improving rural livelihoods and stimulating entrepreneurship in communities living close to the mines. Similarly direct and indirect linkages between the mining sector and the local economy could be enhanced through the provision of food supply to the mine, manufacture of mining inputs, provision of security services and supplying of labour by the local community.

Current trends indicate that effective harnessing of mineral resources for economic and social empowerment could be realized through designing fiscal policy frameworks focusing on economic growth, socio-economic development and poverty reduction. The article also concludes that direct community benefit from mining activities in Gwanda Rural District included road construction and maintenance, rehabilitation of irrigation schemes, drilling of boreholes, construction of primary and secondary schools, sponsorship of sports, completion of local clinics and construction of nurses' houses, construction of dams and provision of employment opportunities.

However the article argues that the focus must shift to economic empowerment of community members through SMEs and job creation ventures. In light of these conclusions the article submits the following recommendations:

That the current Indigenisation and Economic Empowerment Act and the Statutory Instrument for Community Share Ownership Trust legislation must be harmonized with the RDC Act, EMA Act, Mines and Minerals Act and the Communal Lands Management Act to ensure that empowerment is integrated in all legislation focused on rural development.

That Government, Rural District Councils (RDCs) and the Mines must establish a forum where they can engage and agree on the best mechanisms for implementing the Indigenisation and Economic Empowerment legislation as well as the key community empowerment projects

That those local communities are actively involved in initiating and planning community empowerment projects to ensure that the projects to be implemented suit the needs of the communities which are the beneficiaries. 
That the Community Share Ownership Trust development projects use existing development structures as stipulated in the RDC Act (1988), Section 55-60, instead of creating a parallel structure for the management of CSOTs.

\section{Acknowledgements}

This article was written by Funa Moyo who is a lecturer at the Institute of Development StudiesNational University of Science and Technology (NUST) and Dr Clifford Mabhena who is a research fellow at the Institute of Development Studies- National University of Science and Technology (NUST). Thanks to the Gwanda Rural District Council and Sector Ministries, whose officials contributed insights into the study. An appreciation also goes to Mr Mandla Maphosa who is a lecturer at the Institute of Development StudiesNational University of Science and Technology (NUST) for his critical inputs.

\section{References}

[1]. Andres Mejia, A. 2011. The Impact and Effectiveness of Accountability and Transparency Initiatives: The Governance of Natural Resources. London: Institute of Development Studies, University of Sussex.

[2]. Anglo American Case Study, 2011. Anglo American Promoting Sustainable Entrepreneurship. Johannesburg: Business Call for Action

[3]. Bryan, S and Hofmann, B.2007. Transparency and Accountability in Africa's Extractive Industries: The Role of the Legislature. Washington DC: National Democratic Institute for International Affairs.

[4]. Economic Commission for Africa, 2011. Minerals and Africa's Development. The International Study Group Report on Africa's Mineral Regimes. Addis Ababa: United Nations Economic Commission for Africa.

[5]. Frucs, J.M.E. and Agba, A.V. 2007. An Economic Analysis of National Resources Sustainability for the Mining Sector Component- Nigeria. Lagos: Wardell Armstrong International.

[6]. Government of Zimbabwe, 2007. The Indigenization and Economic Empowerment ( General) Regulations SI 21 of 2010 (IEE Regulations . Section 23 of the Indigenisation and Economic Empowerment Act 14 b of 2007. Harare: Government of Zimbabwe.

[7]. Impala Bafokeng Trust (IBT) Annual Report, 2011. Helping to Build Sustainable Communities. Mafikeng: Impala Bafokeng Trust.

[8]. Kanyenze, G, Kondo, T, Chitambara, P and Martens, J. 2011. Beyond The Enclave. Towards a Pro- Poor and Inclusive Development Strategy for Zimbabwe. Harare: Labour and Economic Research Institute of Zimbabwe and Alternatives to NeoLiberalism in Southern Africa.

[9]. Maodza, T. (Senior Reporter) 2012.Community Share Ownership Trusts. 29 June 2012.Harare: The Herald.

[10]. Martin, A. and Taylor, B. 2012. Reap What You Sow: Greed and Corruption in Zimbabwe's Marange Diamond Fields. Canada: Partnership Africa Canada.

[11]. Mate, K. 2002. Communities, Civil Society Organisations and the Management of Mineral Wealth. London: International Institute for Environment and Development ( IIED) No 16.

[12]. Matyzak, D.2012.Digging up the Truth: The legal and Political Realities of Zimplats Saga. Harare: Research and Advocacy Unit.

[13]. Mineral and Petroleum Resources Development Act 2002.Pretoria: Government of South Africa.

[14]. Murombo, T.2010. Law and the indigenisation of mineral resources in Zimbabwe: Any equity for local communities. Johannesburg: University of Witwatersrand.

[15]. Musarurwa, T. (Business Reporter), 2012. Indigenisation Boom for Workers. Harare: The Herald, the Herald Business News, 01 May, 2012.

[16]. O' Connell, A.S. and Lindsay, D. 2011. Development and AID in Sub-Saharan Africa. (Revised Edition). Rome: Swathmore College.

[17]. Pedro, A.M.A.2005. Mainstreaming Mineral Wealth in Growth and Poverty Reduction Strategies. ECA Policy Paper No 1. Addis Ababa: Economic Commission for Africa.

[18]. Saunders, R. 2007. Mining and Crisis in Zimbabwe. Cape Town: Fatal Transactions Campaign and Netherlands Institute for Southern Africa.

[19]. The African National Congress (ANC) Policy Discussion, 2012. State Intervention in the Mineral Sector (SIMS). Maximising the Developmental Impact of the People's Mineral Assets. Johannesburg. The African National Congress.

[20]. United Nations Economic and Social Council. Economic Commission for Africa, 2009. Africa Review Report on Mining. Sixth Session. Addis Ababa: Committee on Food Security and Sustainable Development.

[21]. Weber-Fair, M., Strongman, J. , Kunanayagom, R., Mc Mahan, G and Sheldon, C.2001. Mining and Poverty Reduction.

[22]. Wise, H. and Shtylla, S. 2007. The Role of the Extractive Sector in Expanding Economic Opportunity. New York: Harvard University and John F. Kennedy School of Government.

[23]. Zimbabwe Mining Indaba, 2012. The Zimbabwe Alternative Mining Indaba Declaration, $11^{\text {th }}-13^{\text {th }}$ September 2012 . Harare: Zimbabwe Environmental Law Association, Chiadzwa Community Development Trust (CCDT). 